\title{
KINETICS OF THE ANODIC REACTION OCCURRING DURING THE ELECTROLYSIS OF MOLTEN NITRATES ON PLATINUM ELECTRODES AT DIFFERENT TEMPERATURES*
}

\author{
W. E. Triaca and A. J. Arvía \\ Instituto Superior de Investigaciones, Facultad de Química y Farmacia \\ and División Ingeniería Química, Facultad de Ciencias Fisicomátematicas, \\ Universidad Nacional de La Plata, La Plata, Argentina
}

\begin{abstract}
The kinetics of the anodic reaction occurring during the electrolysis of molten nitrates on bright platinum electrodes has been studied. The kinetic parameters were obtained from conventional current/potential curves, build-up of electrode potential at constant current density and decay of anodic overpotential, working at temperatures between 220 and $470^{\circ} \mathrm{C}$. The current density was varied between 1 and $500 \mathrm{~mA} / \mathrm{cm}^{2}$.

In the region $220-290^{\circ} \mathrm{C}$ the Tafel slope approaches $2 R T / F$ as given by the current/potential curves, but for decay curves, when overpotential is plotted against $\log t$, two straight line portions, one with slope $2 R T / F$ and the other with slope $R T / F$ were observed. The transition from one straight line to the other occurs abruptly. The exchange current densities for both portions were calculated. These results are explained considering a consecutive scheme of reaction where at least two steps differently dependent on electrode potential can be rate-controlling in the mechanism of reaction.

In the range between $350^{\circ} \mathrm{C}$ and above, the Tafel slope is clearly $R T / F$, independent of the method of measurement. The exchange current density was also determined and the mechanism of the reaction interpreted in terms of the increase of oxide-ion concentration with temperature and the discharge of these ions on platinum electrodes.

Résumé--Etude cinétique de la réaction anodique d’électrolyse des nitrates fondus, sur électrodes de platine poli. Les paramètres cinétiques sont obtenus entre 220 et $470^{\circ} \mathrm{C}$ au moyen des courbes courant/tension, accroissement de tension d'électrode à densité de courant constante et chute de surtension anodique. La densité de courant a varié de 1 à $500 \mathrm{~mA} / \mathrm{cm}^{2}$. Dans l'intervalle de température $220-290^{\circ} \mathrm{C}$, la pente de Tafel avoisine $2 R T / F$, selon les courbes courant/tension, mais selon les courbes de chute de surtension (surtension, $\log t$ ), deux droites se manifestent, de pentes respectives $2 R T / F$ et $R T / F$. La transition de l'une à l'autre est brusque. Les densités de courant d'échange ont été calculées pour l'une et l'autre. On interprète ces résultats en supposant au moins deux étapes régulatrices, dépendant différemment de la tension d'électrode. Cependant, à partir et au dessus de $350^{\circ} \mathrm{C}$, la pente de Tafel apparaît uniformément $R T / F$. La densité d'échange a été aussi calculée. Le mécanisme est interprélé comme la décharge des ions oxyde, dont la concentration croît avec la température
\end{abstract}

Zusammenfassung-Es wudre die Kinetik der Anodenreaktionen bei der Elektrolyse von Nitratschmelzen an blanken Platinelektroden untersucht. Die kinetischen Parameter wurden aus konventionellen Strom-Spannungskurven, aus Strom-Zeit-Kurven bei konstanter Stromdichte und aus Abschaltkurven im Temperaturbereich zwischen 220 und $470^{\circ} \mathrm{C}$ ermittelt. Die Stromdichten wurden zwischen 1 und $500 \mathrm{~mA} \mathrm{~cm}^{-2}$ variiert.

Die aus Strom-Spannungskurven bei $220-290^{\circ} \mathrm{C}$ bestimmten Tafel-Steigungen liegen nahe bei $2 R T / F$; hingegen ergeben die aus Abschaltkurven erhaltenen Ueberspannungen, gegen $\log t$ aufgetragenen, zwei lineare Abschnitte, der eine mit der Steigung $2 R T / F$, der andere mit $R T / F$. Der Uebergang der beiden Bereiche erfolgt abrupt. Für beide Bereiche wurden die Austauschstomdichten errechnet. Die Resultate werden gedeutet, indem man eine Reaktionsfolge in Betracht zieht, von der mindestens zwei, in verschiedener Weise potentialabhängige Schritte geschwindigkeitsbestimmend sein können.

Im Temperaturbereich über $350^{\circ} \mathrm{C}$ ist die Tafel-Steigung eindeutig und unabhängig von der Messmethode $R T / F$. Die Austauschstromdichten wurden bestimmt und der Reaktionsmechanismus im Hinblick auf die Zunahme der Oxyd-Ionen-Konzentration mit steigender Temperatur und die Entladung dieser Ionen an der Platinelektrode diskutiert.

* Manuscript received 30 June 1964; part of a thesis submitted by W. E. Triaca in partial fulfillment of the requirements for the Doctor's degree at the University of La Plata. 


\section{INTRODUCTION}

As A part of a research programme on electrochemical reactions on molten salts, the electrolysis of molten nitrates was studied to obtain experimental information about the kinetic parameters of the anodic reaction when platinum electrodes are used, for the purpose of elucidating the mechanism of the electrochemical reaction.

Twenty years ago, Karpatscheff and Patzug1 obtained current/potential curves during the electrolysis of binary and ternary eutectics containing nitrates in the temperature range $150-250^{\circ} \mathrm{C}$. They observed that a Tafel relationship between overvoltage and current density was obeyed.

Recently, after part of this work was submitted for publication, ${ }^{\mathbf{2} 3}$ Jordan, Romberger and Young ${ }^{4}$ have published results on the electrolysis of molten nitrates with a platinum rotating disk electrode, indicating that nitrogen dioxide and oxygen are formed in the anodic reaction.

The kinetic study of electrochemical systems containing molten nitrates is particularly interesting because under certain conditions a reversible electrode is formed on platinum anodes after interruption of the electrolysis current. The significance of the potential of the reversible electrode has been considered in detail before. ${ }^{2}$ Once the thermodynamic aspects of the reaction werc established, its kinetics was studied in an attempt to determine the mechanism of the reaction over a wide range of temperature.

\section{Cell design}

\section{EXPERIMENTAL TECHNIQUE}

The electrolysis cells employed in the present work were essentially of the same design as the cells described in previous papers., ${ }^{\mathbf{5}, 6}$

The cathode of the cell was a silver plate, Ag-1000, of about $90 \mathrm{~cm}^{2}$. The anode was a platinum sheet of $2 \mathrm{~cm}^{2}$ or, in some cases, a platinum wire of $3 \mathrm{~cm}^{2}$. The reference electrode was a silver wire dipped in the electrolyte containing silver ions and placed as in the usual experimental arrangement described elsewhere. The platinum anode was mounted into a glass compartment where the composition of gases could be maintained under control. The cell was thermostatted at $\pm 0 \cdot 5^{\circ} \mathrm{C}$.

\section{Electrolytes}

Two different electrolytes were used, (a) pure silver nitrate and (b) silver nitrate dissolved at various concentrations in a sodium-nitrate-potassium-nitrate mixture (1 mole: 1 mole)

The preparation of the electrolyte was carried out as follows: the ground chemicals were mixed and dried in an oven at $120^{\circ} \mathrm{C}$ for several days. The molten mixture was then filtered through a sintered glass disk conveniently mounted in an all-glass apparatus, which was connected to a conventional vacuum line. The filtration was performed in vacuo and the molten salt was received in a glass container. Once the electrolyte had solidified, the whole system was filled with nitrogen. The container was separated from the purification line and afterwards the electrolyte was transferred to the electrolysis cell.

In some cases, oxygen and nitrogen were bubbled into the anodic compartment. Oxygen was obtained by electrolysis and nitrogen from a commercial compressed gas cylinder. Both gases were purified following the well-known techniques. 


\section{Electrical circuitry}

A conventional electrolysis circuit was employed. To determine the time dependence of the electrode potential, an electronic interrupter was placed in series with the circuit, as indicated in Fig. 1. The electronic interrupter could be controlled with pulses from a pulse generator or manually with a mercury switch. This circuit was essentially based

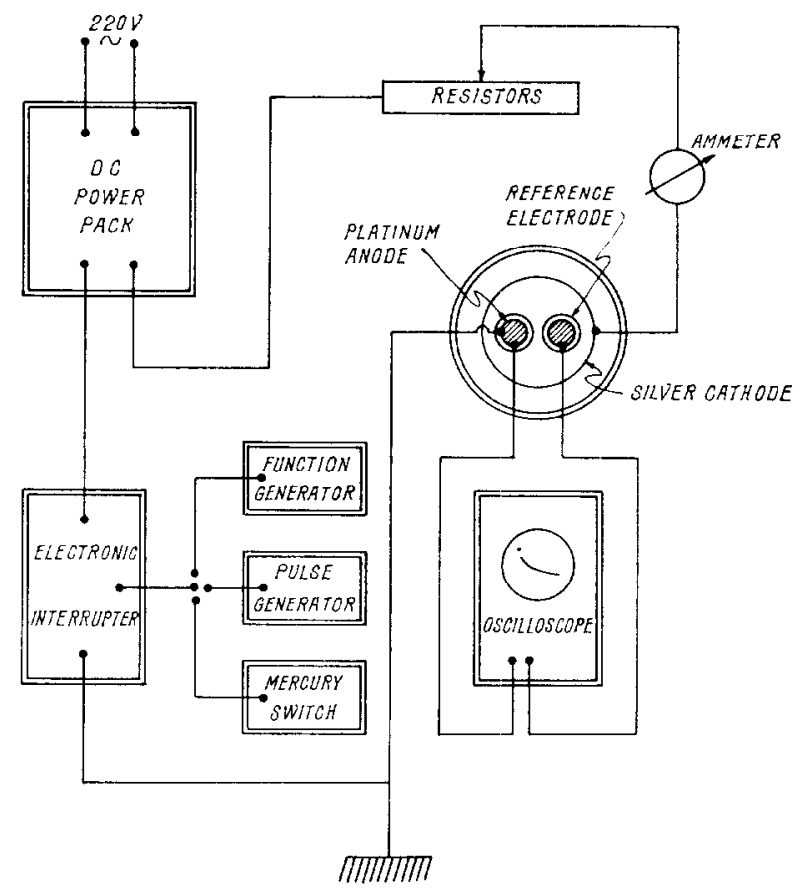

FIG. 1. Scheme of the electrical circuitry used to record build-up and decay curves.

on the interrupter described by Richeson and Eisenberg? ${ }^{7}$, although some modifications were introduced to improve its response and stability.

\section{Procedure}

The following determinations were done in each series of experiments, (a) anodic build-up curves at constant current density, (b) decay of the anodic potential when the electrolysis current was interrupted, (c) determination of current potential curves. The measurements were done either between the anode and the reference electrode or the anode and the cathode of the cell.

The current density was varied from 1 to $500 \mathrm{~mA} / \mathrm{cm}^{2}$ referred to the apparent anode area. The temperature was raised from 220 to $470^{\circ} \mathrm{C}$. The potential was recorded at a rate from $10 \mu \mathrm{s} / \mathrm{cm}$ to $1 \mathrm{~s} / \mathrm{cm}$ read on the oscilloscope screen, and further up to $30 \mathrm{~min}$ with a conventional potentiometric recorder.

\section{RESULTS}

\section{Ohmic overpotential and reference potential}

On Figs. 2 and 3 the shape of build-up and decay of anodic potential respectively can be seen. The dot shown in Fig. 2 corresponds to the reversible potential of the 


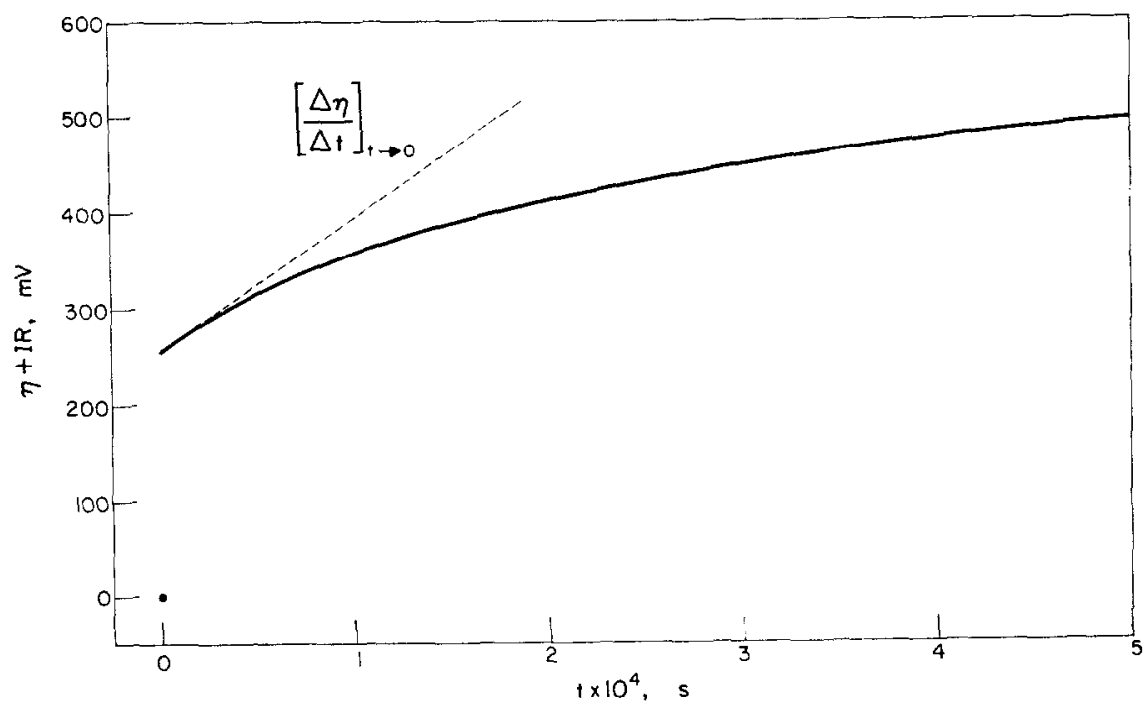

FIG. 2. Oscillographic trace of a build-up curve.

Electrolyte (b), $261^{\circ} \mathrm{C}, 71 \cdot 4 \mathrm{~mA} / \mathrm{cm}^{2}$. C, calculated with eq (3), is $51 \mu \mathrm{F} / \mathrm{cm}^{2}$.

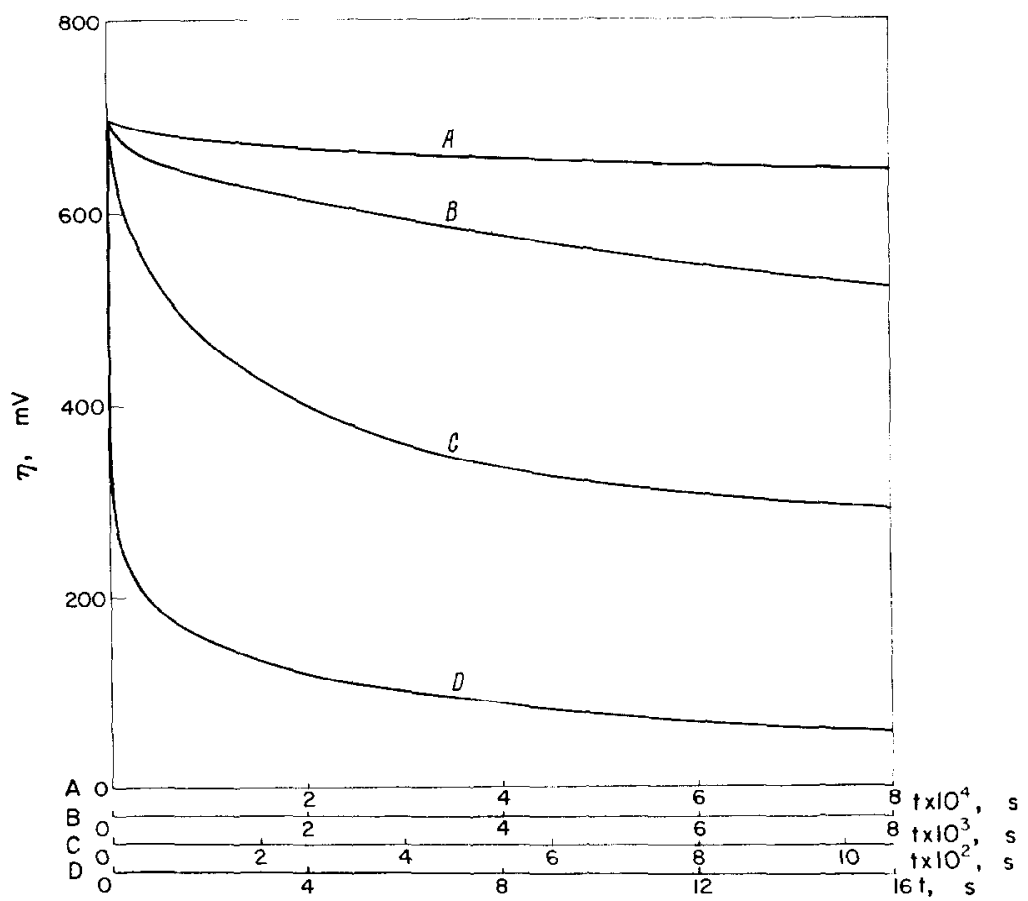

Fig. 3. Decay of anodic overpotential.

A, B, C and D are records obtained at different rates. Electrolyte (b), $261^{\circ} \mathrm{C}, 56.8$ $\mathrm{mA} / \mathrm{cm}^{2}$. 
system and was taken as a reference to calculate the anodic overpotential. The ohmic overpotential between electrodes could be immediately read from the instantaneous drop of potential on the oscillograms and it was plotted against the intensity as shown in Fig. 4. The slopes of the straight lines give the average resistances between electrodes

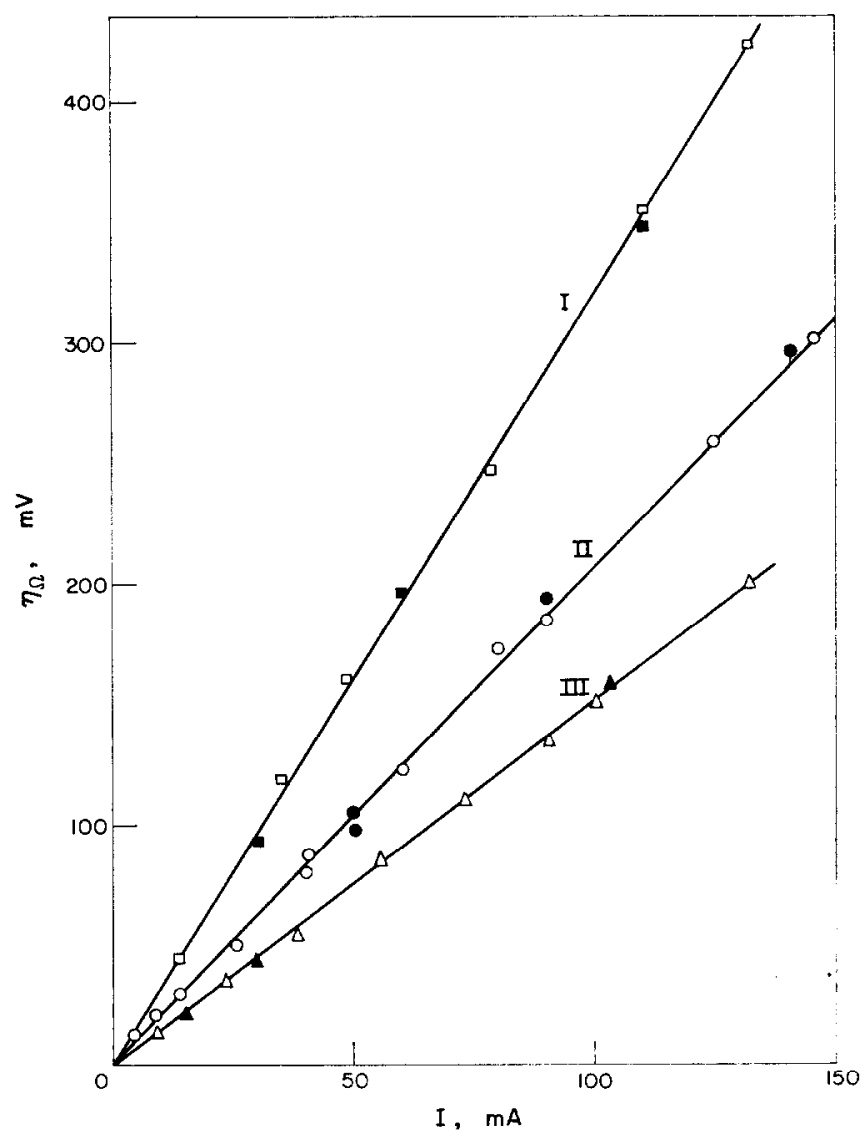

FIG. 4. Ohmic overpotential vs current intensity.

I, II and III refer to experiments with electrolyte (b) at 261,373 and $473^{\circ} \mathrm{C}$ respectively.

which were later used to correct the electrode overpotentials. The ohmic drop between electrodes was also measured with a conventional bridge.

The overpotentials are corrected for ohmic drop and referred to the reversible potential of the residual galvanic cell which correponds to the following equilibrium: ${ }^{2}$

$$
\mathrm{Ag}+\mathrm{NO}_{2}+\frac{1}{2} \mathrm{O}_{2} \rightleftharpoons \mathrm{AgNO}_{3} .
$$

\section{Decay of the anodic overpotential}

The decay of the anodic overpotential was studied by plotting together the curves obtaincd with the oscilloscope and the recorder. The results were also plotted according to the equation ${ }^{8,9}$

$$
\eta_{t}=K-b \log \left(t+b^{\prime} C / i\right)
$$




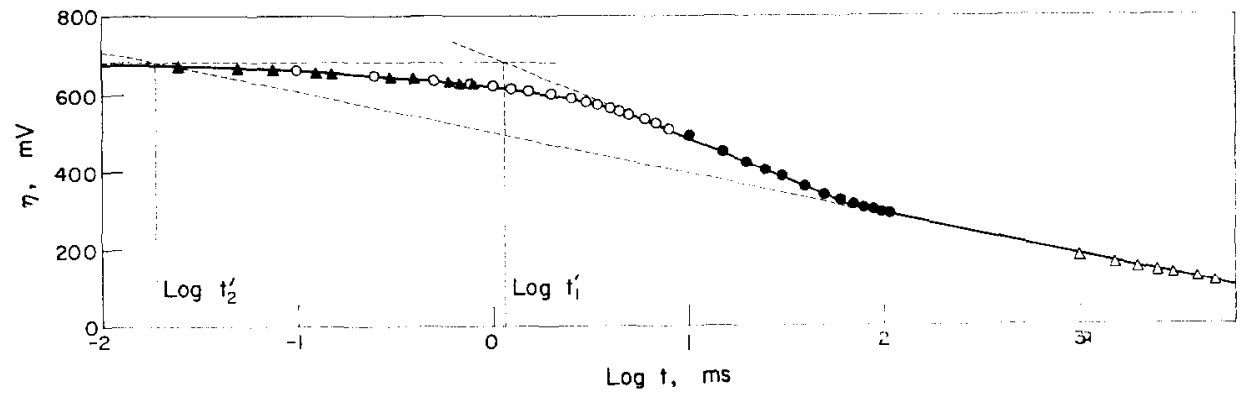

FIG. 5. Decay of overpotential $v s \log$ (time).

Different marks correspond to traces of decay of overpotential recorded at different rates. Electrolyte (b), $261^{\circ} \mathrm{C}, 54.5 \mathrm{~mA} / \mathrm{cm}^{2}$. Straight lines were drawn with slopes $2 R T / F$ and $R T / F$. $t_{1}{ }^{\prime}$ and $t_{2}{ }^{\prime}$ are indicated in the figure.

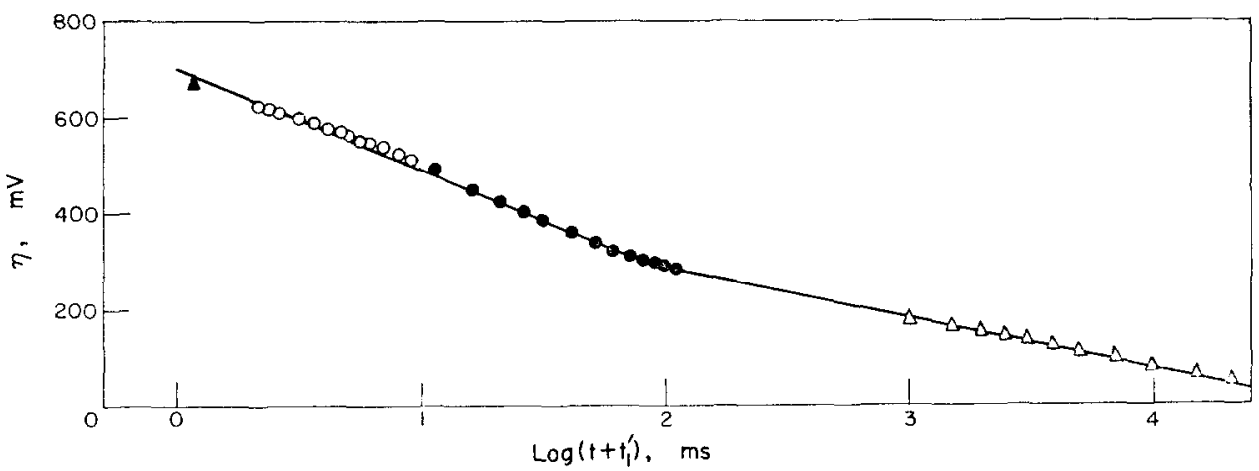

Fig. 6. Decay of overpotential plottcd according to equation (1).

Data from Fig. 5.

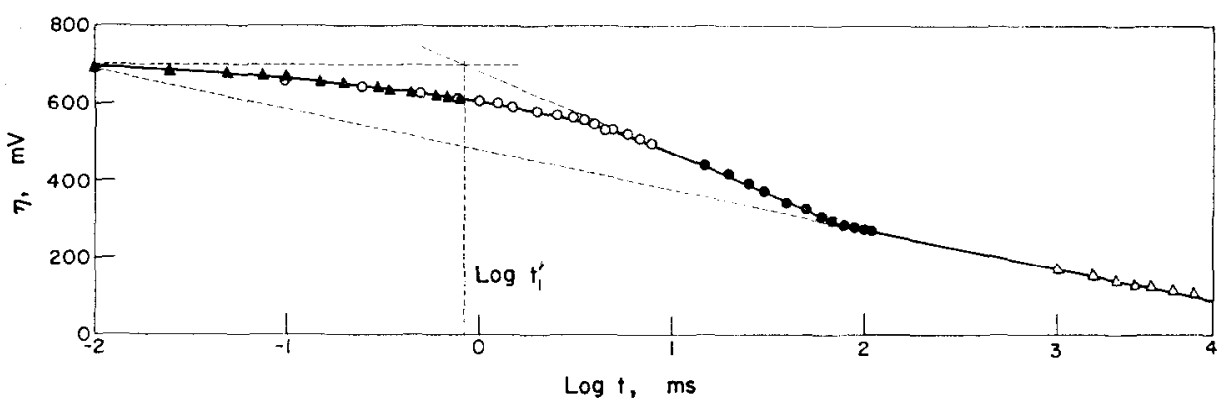

Fig. 7. Decay of overpotential vs $\log$ (time).

Electrolyte (b), $261^{\circ} \mathrm{C}, 100 \mathrm{~mA} / \mathrm{cm}^{2}$.

where $\eta_{t}$ is the overpotential read at time $t$ elapsed since the current interruption, $K$ and $b$ are constants, $b^{\prime}=b / 2 \cdot 303, C$ is the differential capacitance of the electrical double layer and $i$ is the current density at current interruption. Figures 5, 7, 9 and 10 indicate the decay of $\eta$ with $\log t$, and Figs. 6 and 8 show some results according to (1). From these plots $C$ and $b$ were obtained.

The exchange current density $i_{0}$ was also calculated with the relationship ${ }^{10}$

$$
i_{0}=\frac{C b^{\prime}}{t} \exp \left(-\eta_{t} / b^{\prime}\right)
$$




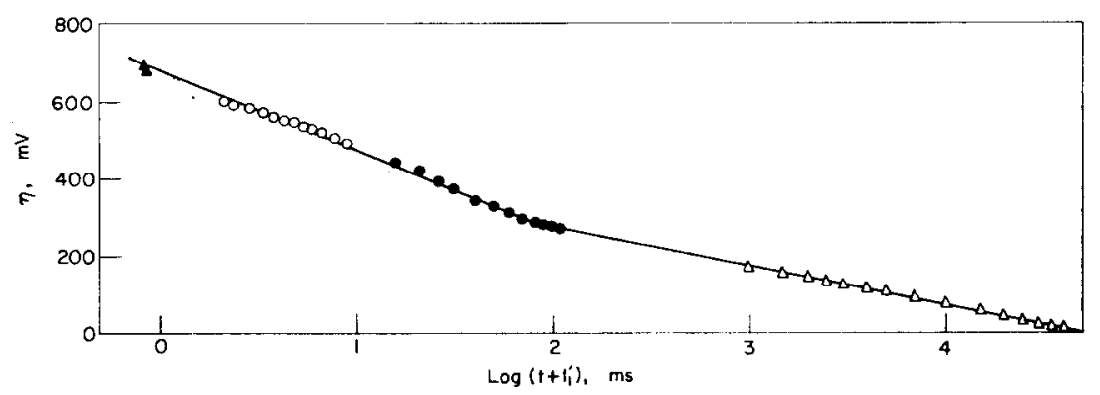

Fig. 8. Decay of overpotential plotted according to equation (1).

Data from Fig. 7.

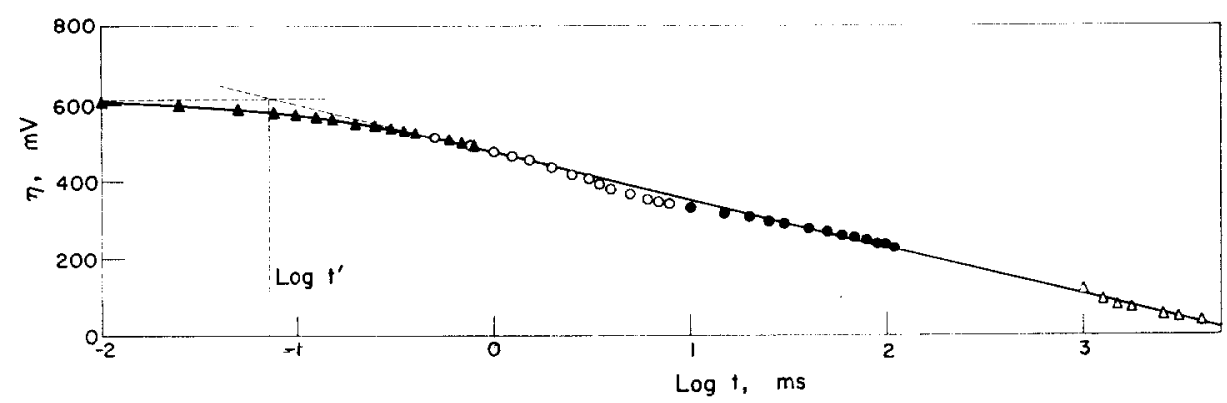

FIG. 9. Decay of overpotential $v s \log$ (time).

Electrolyte (b), $373^{\circ} \mathrm{C}, 48 \cdot 0 \mathrm{~mA} / \mathrm{cm}^{2}$. The straight line is drawn with slope $R T / F$.

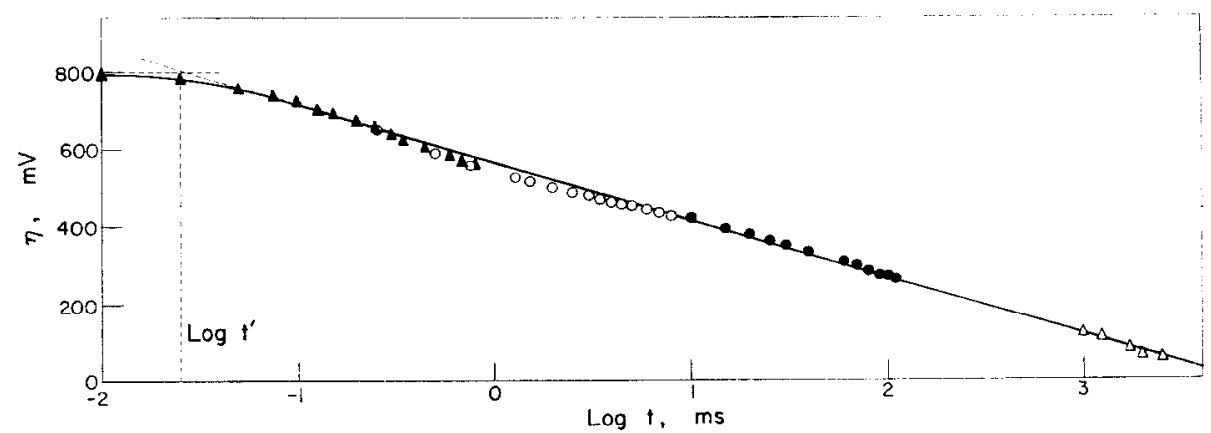

FIG. 10. Decay of overpotential vs (log) time.

Electrolyte (b), $473^{\circ} \mathrm{C}, 71 \cdot 4 \mathrm{~mA} / \mathrm{cm}^{2}$. The straight line is drawn with slope $R T / F$.

Results obtained from decay curves are assembled in Tables $1-4$, where $b_{1}$ and $b_{2}$ (Table 1) are respectively the slopes of the straight line portions of the decay curves and $C$ is the experimental differential capacitance calculated from $t_{1}{ }^{\prime}$.

\section{Build-up curves at constant intensity}

The differential capacitance at the reversible potential was calculated from buildup curves, according to the equation

$$
C=\left[\frac{\mathrm{d} t}{\mathrm{~d} \eta}\right]_{\eta=0} i
$$

where $\mathrm{d} \eta$ is the change of overpotential occurring during the time $\mathrm{d} t$ counted from the 
TABLE 1

Electrolyte (b) $261^{\circ} \mathrm{C}$

\begin{tabular}{|c|c|c|c|c|c|c|c|}
\hline $\begin{array}{c}i \times 10^{3} \\
\mathrm{~A} / \mathrm{cm}^{2}\end{array}$ & $b_{1} \times{ }_{\mathrm{V}} 0^{3}$ & $\begin{array}{c}t_{1}{ }^{\prime} \times 10^{4} \\
\mathrm{~s}\end{array}$ & $\begin{array}{c}C \times 10^{6} \\
\mathrm{~F} / \mathrm{cm}^{2}\end{array}$ & $\begin{array}{c}i_{0} \times 10^{5} \\
\mathrm{~A} / \mathrm{cm}^{2}\end{array}$ & $b_{2} \times{ }_{\mathrm{V}}^{\times 10^{3}}$ & $t_{2}^{\prime} \times 10^{5}$ & $\begin{array}{c}i_{0} \times 10^{8 *} \\
\mathrm{~A} / \mathrm{cm}^{2}\end{array}$ \\
\hline $27 \cdot 3$ & $195 \pm 5$ & $15 \cdot 1 \pm 0 \cdot 5$ & $486 \pm 50$ & 1.4 & $110 \pm 5$ & $7.6 \pm 0.5$ & $4 \cdot 8$ \\
\hline $31 \cdot 8$ & 197 & $13 \cdot 8$ & 513 & $1 \cdot 7$ & 100 & $3 \cdot 3$ & $2 \cdot 3$ \\
\hline $44 \cdot 1$ & 212 & $13 \cdot 2$ & 632 & $2 \cdot 8$ & 106 & $2 \cdot 4$ & $3 \cdot 4$ \\
\hline $54 \cdot 5$ & 212 & $11 \cdot 5$ & 680 & 3.0 & 106 & 1.9 & 4.0 \\
\hline 56.8 & 212 & $11 \cdot 0$ & 678 & $2 \cdot 9$ & 106 & $1 \cdot 6$ & $3 \cdot 4$ \\
\hline $85 \cdot 5$ & 212 & $8 \cdot 7$ & 806 & $3 \cdot 9$ & 106 & $1 \cdot 2$ & 5.6 \\
\hline 100 & 212 & $8 \cdot 3$ & 900 & $4 \cdot 0$ & 105 & 0.8 & 5.4 \\
\hline 120 & 212 & 7.9 & 1030 & $5 \cdot 1$ & 106 & 0.7 & $6 \cdot 0$ \\
\hline
\end{tabular}

* Values calculated with (2) taken $C=48 \times 10^{-6} \mathrm{~F} / \mathrm{cm}^{2}$ and $b_{2}$.

TABLE 2

Electrolyte (b) $373^{\circ} \mathrm{C}$

\begin{tabular}{rlllc}
\hline $\begin{array}{c}i \times 10^{3} \\
\mathrm{~A} / \mathrm{cm}^{2}\end{array}$ & $\begin{array}{c}b \times 10^{3} \\
\mathrm{~V}\end{array}$ & $\begin{array}{c}t^{\prime} \times 10^{5} \\
\mathrm{~s}\end{array}$ & $\begin{array}{c}C \times 10^{6} \\
\mathrm{~F} / \mathrm{cm}^{2}\end{array}$ & $\begin{array}{c}i_{0} \times 10^{7} \\
\mathrm{~A} / \mathrm{cm}^{2}\end{array}$ \\
\hline 3.6 & $133 \pm 5$ & $55.0 \pm 0.5$ & $34 \pm 10$ & $2 \cdot 2$ \\
7.2 & 133 & 41.6 & 52 & 3.4 \\
20.4 & 125 & 15.1 & 57 & 3.7 \\
32.0 & 128 & 11.7 & 67 & 5.0 \\
48.0 & 125 & 6.9 & 61 & $5 \cdot 3$ \\
72.0 & 130 & 5.0 & 64 & $5 \cdot 5$ \\
80.0 & 130 & 5.8 & 82 & 6.3 \\
116 & 130 & 4.2 & 86 & $5 \cdot 4$ \\
\hline
\end{tabular}

TABLE 3

Electrolyte (b) $457^{\circ} \mathrm{C}$

\begin{tabular}{rlllc}
$\begin{array}{c}i \times 10^{3} \\
\mathrm{~A} / \mathrm{cm}^{2}\end{array}$ & $\begin{array}{c}b \times 10^{3} \\
\mathrm{~V}\end{array}$ & $\begin{array}{c}t^{\prime} \times 10^{5} \\
\mathrm{~s}\end{array}$ & $\begin{array}{c}C \times 10^{6} \\
\mathrm{~F} / \mathrm{cm}^{2}\end{array}$ & $\begin{array}{c}i_{0} \times 10^{7} \\
\mathrm{~A} / \mathrm{cm}^{2}\end{array}$ \\
\hline 52.8 & $137 \pm 5$ & $3.5 \pm 0.5$ & $31 \pm 10$ & 2.4 \\
66.6 & 145 & 2.4 & 25 & $3 \cdot 1$ \\
94.7 & 145 & 2.5 & 38 & $5 \cdot 9$ \\
124 & 145 & 1.4 & 28 & $5 \cdot 3$ \\
\hline
\end{tabular}

TABLE 4

Electrolyte (b) $473^{\circ} \mathrm{C}$

\begin{tabular}{clllc}
\hline $\begin{array}{c}i \times 10^{3} \\
\mathrm{~A} / \mathrm{cm}^{2}\end{array}$ & $\begin{array}{c}b \times 10^{3} \\
\mathrm{~V}\end{array}$ & $\begin{array}{c}t^{\prime} \times 10^{5} \\
\mathrm{~s}\end{array}$ & $\begin{array}{c}C \times 10^{6} \\
\mathrm{~F} / \mathrm{cm}^{2}\end{array}$ & $\begin{array}{c}i_{0} \times 10^{7} \\
\mathrm{~A} / \mathrm{cm}^{2}\end{array}$ \\
\hline $52 \cdot 2$ & $148 \pm 5$ & $4 \cdot 0 \pm 0.5$ & $32 \pm 10$ & $3 \cdot 1$ \\
71.4 & 148 & $2 \cdot 5$ & 28 & $2 \cdot 7$ \\
73.5 & 148 & 2.7 & 31 & $3 \cdot 1$ \\
94.3 & 148 & 2.5 & 37 & 3.9 \\
\hline
\end{tabular}

starting of the electrolysis at constant current density, $i$. Therefore the slope at the origin of build-up curve, as shown in Fig. 2, yields the experimental differential capacitance at the reversible potential. Results are assembled in Table 5.

\section{Current/potential curves}

The dependence of the overpotential on current density is given by Tafel equation

$$
\eta=a+b \log i
$$


TABLE 5

\begin{tabular}{ccl}
\hline $\begin{array}{c}T \\
{ }^{\circ} \mathrm{C}\end{array}$ & $\begin{array}{c}i \times 10^{3} \\
\mathrm{~A} / \mathrm{cm}^{2}\end{array}$ & $\begin{array}{c}C \times 10^{6} \\
\mathrm{~F} / \mathrm{cm}^{2}\end{array}$ \\
\hline 261 & $27 \cdot 0$ & $52+5$ \\
& $31 \cdot 8$ & 50 \\
& $57 \cdot 0$ & 44 \\
& $85 \cdot 5$ & 46 \\
& 100 & 50 \\
373 & $6 \cdot 8$ & 37 \\
& $32 \cdot 0$ & 40 \\
& $72 \cdot 0$ & 67 \\
& 112 & 49 \\
387 & 116 & 58 \\
& $36 \cdot 5$ & 61 \\
457 & $54 \cdot 0$ & 36 \\
& $94 \cdot 7$ & 45 \\
& 124 & 33 \\
\hline
\end{tabular}

where $a$ and $b$ are constants to be calculated for the experimental results, $a$ being equal to $-b \log i_{0}$. From the $\eta v s \log i$ plot, $b$ and $i_{0}$ are obtained. Some Tafel plots obtained under different conditions are shown in Fig. 11. The results obtained from

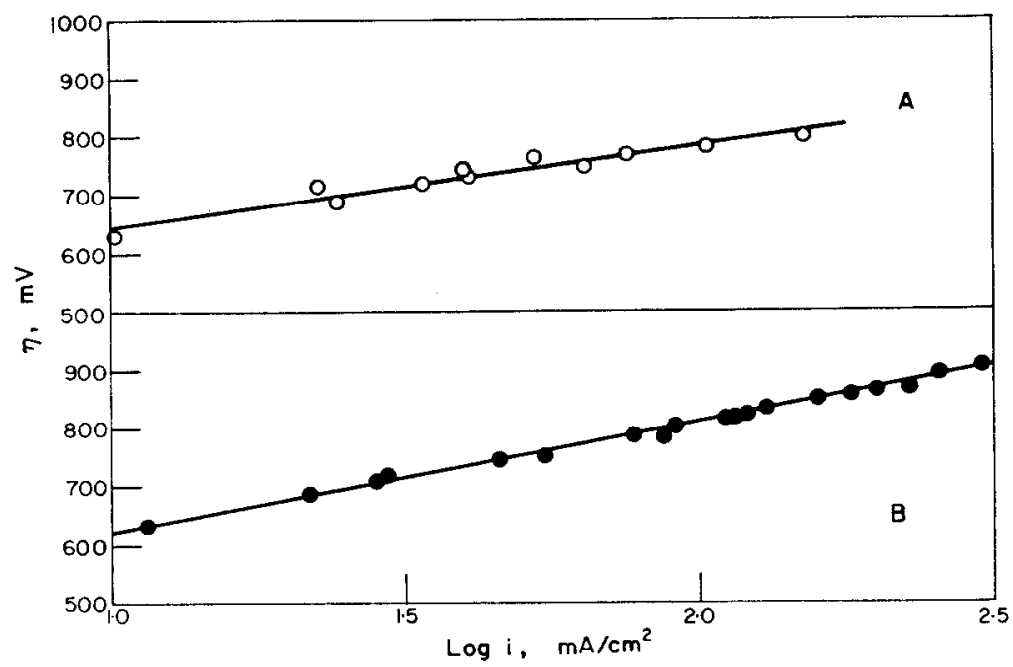

FIG. 11. Tafel plots at different temperatures. A, Electrolyte (b), $380^{\circ} \mathrm{C}$. B, Electrolyte (a), $226^{\circ} \mathrm{C}$.

Tafel plots are assembled in Table 6 . The values of $i_{0}$ were calculated with slopes $2 R T / F$ and $R T / F$ for the low and high temperature experiments, respectively.

5. Temperature effect on exchange current density

In the range of temperature in which the Tafel slope is $2 R T / F$, we can estimate the experimental energy of activation, $E_{a}$, by plotting $\log i_{0}$ vs $1 / T$, where $T$ is the temperature in ${ }^{\circ} \mathrm{K}$. The result is $E_{a}=8 \cdot 2 \pm 1.5 \mathrm{Kcal} / \mathrm{mol}$. 
TABLE 6

\begin{tabular}{ccccc}
\hline $\begin{array}{c}T \\
{ }^{\circ} \mathrm{C}\end{array}$ & Electrolyte & $\begin{array}{c}b \times 10^{3} \\
\mathrm{~V}\end{array}$ & $\begin{array}{c}(2.303 R T / F) \times 10^{3} \\
\mathrm{~V}\end{array}$ & $\begin{array}{c}i_{0} \times 10^{6} \\
\mathrm{~A} / \mathrm{cm}^{2}\end{array}$ \\
\hline 221 & (a) & $210 \pm 10$ & 98.0 & 7.9 \\
226 & (a) & 185 & 99.0 & 8.0 \\
242 & (b) & 205 & 102.3 & 8.9 \\
256 & (b) & 206 & 105.0 & 13.5 \\
278 & (a) & 219 & 109.5 & 15.9 \\
305 & (b) & 160 & 115.0 & - \\
340 & (a) & 166 & 122.0 & - \\
380 & (b) & 138 & 130.0 & 0.17 \\
458 & (b) & 145 & 145.0 & 0.66 \\
\hline
\end{tabular}

\section{INTERPRETATION}

The experimental results show the existence of three different regions of temperature where the constant $b$ approaches different values.

In the range of temperature between 220 and $290^{\circ} \mathrm{C}$ approximately, the constant $b$ resulting from current/potential curves is clcarly $2 R T / F$. Within this range of temperature and at a high current density the decay curves give two different slopes: initially, at high overpotentials the first straight line portion of the $\eta v s \log t$ curve has also a slope $2 R T / F$, but after about $100 \mathrm{~ms}$ of the current interruption, when a lower overpotential still exists on the electrode, the slope of the straight line portion changes, relatively abruptly, to $R T / F$. For the former case the corresponding exchange current is about $10^{-5} \mathrm{~A} / \mathrm{cm}^{2}$ and for the latter about $10^{-8} \mathrm{~A} / \mathrm{cm}^{2}$, as obtained from (2).

The average experimental differential capacitance of the electrical double layer calculated from the build-up curves is $48 \pm 10 \mu \mathrm{F} / \mathrm{cm}^{2}$, which is a reasonable low value, supporting the assumption we can neglect any roughness effect on the electrode surface. However, the case for decay curves is different, as the experimental differential capacitance depends on the choice of the straight line portion used in the extrapolation. If the slope $R T / F$ is considered the experimental capacitance coincides in this case with the values previously calculated from build-up curves, but if the straight line of $2 R T / F$ slope is taken, capacitances one order of magnitude higher are obtained. Nevertheless, taken into account the values of $t^{\prime}$ required to linearize the decay curves, we assign significance to the capacitances obtained with $2 R T / F$ slope. We must also point out that in the present conditions it is difficult to compare capacitances resulting from build-up and decay curves, since they are referred to different electrode potentials.

At the highest temperature, between 350 and $470^{\circ} \mathrm{C}$, the Tafel slopes are always equal to $R T / F$, whatever the way they are evaluated. Capacitances are in this case low, as can be expected for a simple structure of the electrical double layer. 'The exchange current density is here between $10^{-6}$ and $10^{-7} \mathrm{~A} / \mathrm{cm}^{2}$.

There is an intermediate temperature region of about $290-350^{\circ} \mathrm{C}$ where the Tafel slopes are defined neither in terms of $2 R T / F$ nor $R T / F$. However, the experimental results satisfied the equations related to electrochemical activated processes.

The foregoing results indicate that in the anodic reaction occurring during the electrolysis of molten nitrates we are dealing with an activated process involving a complex reaction depending on temperature. Hence, to discuss the most likely 
mechanisms which could explain those results, we must begin by distinguishing between low and high temperature electrolysis.

\section{DISCUSSION}

\section{Analysis of some paths and rate-determining steps in the anodic reaction} occurring during the electrolysis of molten nitrates

For an ordinary electrode for which the activation polarization can be represented by the Tafel equation, the decay of overpotential is quite generally logarithmic in the time of decay measured from the moment of cessation of the polarizing current. This relationship holds over wide ranges of time, except at very short times after the interruption of the polarizing current or near the reversible potential for the process concerned.

According to the empirically chosen value of $t^{\prime}$ two linear logarithmic regions are obtained at low temperature and only one at high temperature, as shown in Figs. $6,8,9$ and 10 . We must emphasize that no value of $t^{\prime}$ could be found for the experiments at low temperature which gives a single straight line for the overpotential/log (time) plot.

The plots shown in Figs. 5, 6, 7 and 8 indicate a complex behaviour of the anodic reaction at low temperature, more than one rate-determining mechanism being involved in the discharge of the electrode. The slopes shown there are characteristic of several steps as found for the anodic evolution of oxygen in the aqueous,medium. ${ }^{11}$ The higher slope of $2 R T / F$ was found also through direct polarization measurements.

As shown in Figs. 9 and 10, the behaviour of the anodic reaction at higher temperatures seems simpler than at lower. Finally it should be pointed out that in no case was a significative dependence of Tafel slope with current density observed.

Therefore, to interpret the electrochemical reaction we must analyse the various rate-determining steps which could explain the kinetics of the reaction.

To postulate the probable mechanism taking into account the experimental results we shall assume that a scheme of consecutive reactions is involved in the anodic process. The analysis is limited in principle to the following three fundamental reaction schemes, the different possibilities of which will be considered later.

Mechanism A

$$
\mathrm{NO}_{3}^{-}+\mathrm{Pt} \rightleftharpoons \mathrm{NO}_{2}+(\mathrm{O}) \mathrm{Pt}+\mathrm{e},
$$

$(\mathrm{O}) \mathrm{Pt}+(\mathrm{O}) \mathrm{Pt} \rightleftharpoons \mathrm{O}_{2}+2 \mathrm{Pt}$,

$$
\mathrm{NO}_{3}^{-}+(\mathrm{O}) \mathrm{Pt} \rightleftharpoons \mathrm{NO}_{2}+\mathrm{O}_{2}+\mathrm{Pt}+\mathrm{e} .
$$

Mechanism B

$$
\begin{aligned}
\mathrm{NO}_{3}{ }^{-}+\mathrm{Pt} & \rightleftharpoons\left(\mathrm{NO}_{3}\right) \mathrm{Pt}+\mathrm{e}, \\
\left(\mathrm{NO}_{3}\right) \mathrm{Pt} & \rightleftharpoons(\mathrm{O}) \mathrm{Pt}+\mathrm{NO}_{2},
\end{aligned}
$$

$(\mathrm{O}) \mathrm{Pt}+(\mathrm{O}) \mathrm{Pt} \rightleftharpoons \mathrm{O}_{2}+2 \mathrm{Pt}$,

Mechanism C

$$
\mathrm{NO}_{3}^{-}+(\mathrm{O}) \mathrm{Pt} \rightleftharpoons \mathrm{NO}_{2}+\mathrm{O}_{2}+\mathrm{Pt}+\mathrm{e} .
$$

$$
\begin{aligned}
\mathrm{NO}_{3}^{-} & \rightleftharpoons \mathrm{O}^{2-}+\mathrm{NO}_{2}^{+}, \\
\mathrm{O}^{2-}+\mathrm{Pt} & \rightleftharpoons(\mathrm{O}) \mathrm{Pt}+2 \mathrm{e}, \\
(\mathrm{O}) \mathrm{Pt}+(\mathrm{O}) \mathrm{Pt} & \rightleftharpoons \mathrm{O}_{2}+2 \mathrm{Pt}, \\
\mathrm{NO}_{3}-+(\mathrm{O}) \mathrm{Pt} & \rightleftharpoons \mathrm{O}_{2}+\mathrm{NO}_{2}+\mathrm{Pt}+\mathrm{e}, \\
\mathrm{NO}_{3}{ }^{-}+\mathrm{NO}_{2}^{+} & \rightleftharpoons 2 \mathrm{NO}_{2}+\frac{1}{2} \mathrm{O}_{2} .
\end{aligned}
$$

Symbols in brackets indicate radicals or atoms on the electrode surface. 
The kinetic analysis could be handled by applying Christiansen's method ${ }^{12,13}$ as extended by Bockris ${ }^{14}$ to electrochemical reactions. According to this treatment for a consecutive scheme containing $i$ reversible steps, the rate equation of the total reaction is obtained by solving a set of linear equations involving the concentration of intermediates. The rate of the total reaction is given by:

where

$$
v=v_{+}-v_{-}
$$

and

$$
\frac{1}{v_{+}}=\frac{1}{w_{1}}+\frac{w_{-1}}{w_{1} w_{2}}+\frac{w_{-1} w_{-2}}{w_{1} w_{2} w_{3}}+\cdots+\frac{w_{-1} w_{-2} \cdots w_{-(i-1)}}{w_{1} w_{2} w_{3} \cdots w_{i}}
$$

$$
\frac{1}{v_{-}}=\frac{1}{w_{-i}}+\frac{w_{i}}{w_{-i} w_{-(i-1)}}+\cdots+\frac{w_{i} w_{i-1} \cdots w_{2}}{w_{-i} w_{-(i-1)} \cdots w_{-1}}
$$

$w_{1}=k_{1} a_{1}$ and $w_{-i}=k_{-i} b_{i}$ and $a_{1}$ and $b_{i}$ are the concentrations of the initial reacting species entering both rcactions (in the positive and ncgative dircctions). $w_{i}$ (for $i=$ $2,3, \ldots i$ ) is the probability per second assisting step $i$ in the positive direction. $w$ can be a constant or dependent on concentration of stable entities and, if the partial reaction involves an electron transfer, it is also dependent on the electrode potential.

Mechanism A. This involves three possibilities (a) reaction (A1) is the rate determining step (b) reaction (A1) is followed by (A2) and the latter is rate-determining step and (c) reaction (A1) is followed by (A3), the latter being the rate-determining step.

Possibility ( $a$ ). Let $X O$ be the fraction of the electrode surface covered by oxygen atoms. If (A1) is rate-determining, it is reasonable to take $X \mathrm{O} \rightarrow 0$ and the rate equation turns out to be

$$
v_{1}=k_{1} a_{\mathrm{No}_{3}}-\exp (\alpha \Delta \varphi F / R T)
$$

where $k_{1}$ is the specific rate constant of (A1), $\Delta \varphi$ the potential difference in the electrical double layer where reaction occurrs, $a_{\mathrm{NO}_{3}}{ }^{-}$the activity of the reacting species, and $\alpha$ the transfer coefficient assisting the anodic reaction (equal to $\beta z$, the symmetry factor $\beta$ being taken equal to $0 \cdot 5$ ). In the present case $\alpha=0.5$.

If $a_{\mathrm{NO}_{3}}$ - in the melt is taken as unity, the rate equation is

$$
v_{1}=k_{1} \exp (\Delta \varphi F / 2 R T),
$$

and according to the definition of the term $w$, we have

$$
w_{1}=k_{1} \exp (\Delta \varphi F / 2 R T) \text {. }
$$

Considering equation (6), the rate of the total reaction is given by

$$
v=k_{1} \exp (\Delta p F / 2 R T)
$$

and the rate equation written in terms of current density is

$$
i_{a}=z F k_{1} \exp (\Delta \varphi F / 2 R T) \text {. }
$$

Therefore the Tafel slope in this case is $b=2 R T / F$.

Possibility (b). It is reasonable to assume in this case that $X O$ has an appreciable value proportional to the activity or concentration of oxygen atoms at the surfaces $X \mathrm{O}=k^{\prime} a_{\mathrm{O}}$, where $k^{\prime}$ is a factor of proportionality between activity and degree of 
coverage of oxygen atoms. Hence, the rate equations of the partial reactions are

$$
\begin{aligned}
v_{1} & =k_{1} a_{\mathrm{NO}_{3}}\left(1-k^{\prime} a_{\mathrm{O}}\right) \exp (\Delta \varphi F / 2 R T), \\
v_{-1} & =k_{-1} k^{\prime} a_{\mathrm{O}} a_{\mathrm{NO}_{\mathrm{a}}} \exp (-\Delta \varphi F / 2 R T), \\
v_{2} & =k_{2} k^{\prime 2} a_{\mathrm{O}}{ }^{2}
\end{aligned}
$$

Assuming that $a_{\mathrm{NO}_{\mathrm{a}}} \approx 1=a_{\mathrm{NO}_{\mathrm{a}}}$, we have

$$
\begin{aligned}
w_{1} & =k_{1} \exp (\Delta \varphi F / 2 R T), \\
w_{-1} & =k_{1} \exp (\Delta \varphi F / 2 R T)+k_{-1} \exp (-\Delta \varphi F / 2 R T), \\
w_{2} & =k_{2} k^{\prime} a_{0},
\end{aligned}
$$

and according to (6)

$$
\frac{1}{v}=\frac{1}{k_{1} \exp (\Delta \varphi F / 2 R T)}+\frac{k_{1} \exp (\Delta \varphi F / 2 R T)+k_{-1} \exp (-\Delta \varphi F / 2 R T)}{k_{1} k_{2} k^{\prime} a_{0} \exp (\Delta \varphi F / 2 R T)}
$$

Since (A1) is at quasi-equilibrium for low $\Delta \varphi$, the steady activity or concentration of oxygen atoms can be immediately obtained as

$$
a_{\mathrm{o}}=\frac{K_{1} \exp (\Delta \varphi F / R T)}{k^{\prime}}
$$

where $K_{1}=k_{1} / k_{-1}$. Considering that $k_{1} \gg k_{2}$, from (19) and (20) the rate equation becomes

Then $b=R T / 2 F$.

$$
v=K_{1}^{2} k_{2} \exp (2 \Delta \varphi F / R T) \text {. }
$$

At large overpotentials, the current flowing through the system, according to (19), approaches a value which is independent of overpotential, thus reaching a limiting value

$$
v=k_{2} k^{\prime}\left(a_{\mathrm{O}}\right)_{\mathrm{sat}}
$$

therefore the Tafel slope approaches infinity.

Possibility $(c)$. We start by assuming that the degree of surface coverage by oxygen atoms is appreciable. The rate equations of the partial reactions are (13) and (14), and

$$
v_{3}=k_{3} k^{\prime} a_{0} a_{\mathrm{NO}_{3}}-\exp (\Delta \varphi F / 2 R T)
$$

Hence, the probability factors are given by (16) and (17) and

Therefore, (6) yields

$$
w_{3}=k_{3} \exp (\Delta \varphi F / 2 R T) \text {. }
$$

$$
\frac{1}{v}=\frac{1}{k_{1} \exp (\Delta \varphi F / 2 R T)}+\frac{k_{1} \exp (\Delta \varphi F / 2 R T)+k_{-1} \exp (-\Delta \varphi F / 2 R T)}{k_{1} k_{3} \exp (\Delta \varphi F / R T)} .
$$

Considering that $k_{1} \gg k_{3}$, at lower overpotentials we obtain

$$
v=K_{1} k_{3} \exp (3 \Delta p F / 2 R T)
$$

and $b$ approaches the value $2 R T / 3 F$.

Under those conditions, at large overpotentials, (25) becomes

and $b$ is $2 R T / F$.

$$
v=k_{3} \exp (\Delta \varphi F / 2 R T) \text {. }
$$


Mechanism $B$. In this mechanism we have at least four possibilities (a) reaction (B1) is the rate-determining step (b) reaction (B1) is followed by (B2), the latter being the rate-determining step (c) reactions $(\mathrm{B} 1)$ and $(\mathrm{B} 2)$ are followed by $(\mathrm{B} 3)$, where the latter is the rate-determining stcp and (d) reactions (B1) and (B2) are followed by (B4), which is the rate-controlling step.

Possibility (a). In this case it can be assumed as a first approximation, that the degree of coverage by $\mathrm{NO}_{3}$ radicals is negligible: $X_{\mathrm{NO}_{3}}=k^{\prime \prime} a_{\mathrm{NO}_{3}} \ll 1$, and proceeding as in mechanism A, possibility (a), the Tafel slope is $2 R T / F$.

Possibility (b). Let us consider that the degree of coverage by $\mathrm{NO}_{3}$ radicals is appreciable, therefore the rate equation for the partial reactions are:

Hence,

$$
\begin{aligned}
v_{1} & =k_{1} a_{\mathrm{No}_{3}}\left(1-k^{\prime \prime} a_{\mathrm{NO}_{3}}\right) \exp (\Delta \varphi F / 2 R T), \\
v_{-1} & =k_{-1} k^{\prime \prime} a_{\mathrm{NO}_{3}} \exp (-\Delta \varphi F / 2 R T), \\
v_{2} & =k_{2} k^{\prime \prime} a_{\mathrm{NO}_{3}} .
\end{aligned}
$$

$$
\begin{aligned}
w_{1} & =k_{1} \exp (\Delta \varphi F / 2 R T), \\
w_{-1} & =k_{1} \exp (\Delta \varphi F / 2 R T)+k_{-1} \exp (-\Delta \varphi F / 2 R T), \\
w_{2} & =k_{2} .
\end{aligned}
$$

Finally, as expressed by (6) we have

$$
\frac{1}{v}=\frac{1}{k_{1} \exp (\Delta \varphi F / 2 R T)}+\frac{k_{1} \exp (\Delta \varphi F / 2 R T)+k_{-1} \exp (-\Delta \varphi F / 2 R T)}{k_{1} k_{2} \exp (\Delta \varphi F / 2 R T)} .
$$

Assuming that $k_{1} \gg k_{2}$, at low overpotentials, (34) yields

and consequently $b=R T / F$.

$$
v=K_{1} k_{2} \exp (\Delta \varphi F / R T),
$$

At large overpotentials, according to (34), $v$ approaches $k_{2}$ and $b \rightarrow \infty$.

Possibility (c). The degree of coverage can be expressed as the addition of two terms: one fraction of it corresponds to the coverage of $\mathrm{NO}_{3}$ radicals formed on the electrode surface and the rest of it to oxygen atoms. Assuming that the degree of coverage in both cases is proportional to the activity of the reacting species, we have

$$
X=X_{\mathrm{NO}_{\mathrm{a}}}+X_{\mathrm{O}}=k^{\prime \prime} a_{\mathrm{NO}_{3}}+k^{\prime} a_{\mathrm{O}} .
$$

Due to the fact the reaction (B3) is the rate-determining one, we further assume that $X_{\mathrm{NO}_{3}} \rightarrow 0$ but that $X_{\mathrm{O}}$ is appreciable. Therefore the equation, of the partial reactions are

$$
\begin{aligned}
v_{1} & =k_{1}\left(1-k^{\prime} a_{\mathrm{O}}\right) \exp (\Delta \varphi F / 2 R T), \\
v_{-1} & =k_{-1} k^{\prime \prime} a_{N O_{3}} \exp \left(-\Delta_{\varphi} F / 2 R T\right), \\
v_{2} & =k_{2} k^{\prime \prime} a_{\mathrm{No} o_{3}}, \\
v_{-2} & =k_{-2} k^{\prime} a_{O}, \\
v_{3} & =k_{3} k^{\prime \prime 2} a_{0}{ }^{2} .
\end{aligned}
$$

Considering the expression for the intermediates resulting from the quasi-equilibrium 
involved in (B2), we have:

$$
\begin{aligned}
w_{1} & =k_{1} \exp (\Delta \varphi F / 2 R T), \\
w_{-1} & =K_{2} k_{1} \exp (\Delta \varphi F / 2 R T)+k_{-1} \exp (-\Delta \varphi F / 2 R T), \\
w_{2} & =k_{2}, \\
w_{-2} & =k_{-2}, \\
w_{3} & =k_{3} k^{\prime} a_{0},
\end{aligned}
$$

and proceeding as before with (42), (43), (44), (45) and (46), (6) yields:

$$
\begin{array}{r}
\frac{1}{v}=\frac{1}{k_{1} \exp (\Delta \varphi F / 2 R T)}+\frac{K_{2} k_{1} \exp (\Delta \varphi F / 2 R T)+k_{-1} \exp (-\Delta \varphi F / 2 R T)}{k_{1} k_{2} \exp (\Delta \varphi F / 2 R T)} \\
+\frac{K_{2} k_{1} k_{-2} \exp (\Delta \varphi F / 2 R T)+k_{-1} k_{-2} \exp (-\Delta \varphi F / 2 R T)}{k_{1} k_{2} k_{3} k^{\prime} a_{O} \exp (\Delta \varphi F / 2 R T)} .
\end{array}
$$

At low overpotentials, the quasi-equilibrium involved in (B1) and (B2) yields

$$
a_{\mathrm{o}}=\frac{K_{1} K_{2}}{k^{\prime}} \exp (\Delta \varphi F / R T)
$$

If (B3) is the rate-determining step, then $k_{1} \approx k_{2} \gg k_{3}$ and from (47) and (48) we have and $b$ approaches $R T / 2 F$.

$$
v=K_{1}^{2} K_{2}^{2} k_{3} \exp (2 \Delta \varphi F / R T),
$$

For large overpotentials the rate of reaction approaches the following expression independent of the electrode potential,

and Tafel slope tends to infinity.

$$
v=k_{3} k^{\prime}\left(a_{\mathrm{o}}\right)_{\mathrm{sat}},
$$

Possibility $(d)$. In analogy to possibility (c), the rate equations of the partial reactions are (37), (38), (39), (40) and

$$
v_{4}=k_{4} k^{\prime} a_{\mathrm{O}} \exp (\Delta \varphi F / 2 R T) \text {. }
$$

In addition to (42), (43), (44) and (45), we have also

$$
w_{4}=k_{4} \exp (\Delta \varphi F / 2 R T),
$$

and considering (6) we obtain

$$
\begin{aligned}
\frac{1}{v}=\frac{1}{k_{1} \exp (\Delta \varphi F / 2 R T)}+\frac{K_{2} k_{1} \exp (\Delta \varphi F / 2 R T)+k_{-1} \exp (-\Delta \varphi F / 2 R T)}{k_{1} k_{2} \exp (\Delta \varphi F / 2 R T)} \\
+\frac{K_{2} k_{1} k_{-2} \exp (\Delta \varphi F / 2 R T)+k_{-1} k_{-2} \exp (-\Delta \varphi F / 2 R T)}{k_{1} k_{2} k_{4} \exp (\Delta \varphi F / R T)} .
\end{aligned}
$$

Possibility (d) involves the assumption that $k_{1} \approx k_{2} \gg k_{4}$, hence the rate equation at low overpotentials becomes

$$
v=K_{1} K_{2} k_{4} \exp (3 \Delta p F / 2 R T)
$$

and Tafel slope approaches the value $2 R T / 3 F$.

At large overpotentials (53) changes into

and consequently $b=2 R T / F$.

$$
v=k_{4} \exp (\Delta \varphi F / 2 R T)
$$


Mechanism $C$. To deal with mechanism $\mathrm{C}$ we must first consider that nitrate ions in the molten state are dissociated into nitryl $\left(\mathrm{NO}_{2}^{+}\right)$and oxide $\left(\mathrm{O}^{2-}\right)$ ions..$^{15.16}$ On the basis of the experimental results we start by assuming that the dissociation reaction of nitrate ions is a very fast process and therefore has no possibility of becoming the rate-determining step. Reaction (C5) is also discarded for the same reasons.

Then there are at least three possibilities (a) reaction (C2) is the rate-determining step (b) reaction (C2) is followed by (C3) which is the rate-determining step and (c) reaction $(\mathrm{C} 2)$ is followed by $(\mathrm{C} 4)$, the latter being the rate-controlling one.

Possibility (a). The degree of coverage is assumed very small and the rate equation is then

$$
v_{2}=k_{2} a_{\mathrm{O}^{2}-} \exp (\Delta \varphi F / R T),
$$

since we have also assumed that the symmetry factor is 0.50 and consequently $\alpha=1$. Proceeding as before, we have

$$
w_{2}=k_{2} a_{0^{2-}} \exp (\Delta \varphi F / R T),
$$

and considering reaction $(\mathrm{Cl})$ and taking $a_{\mathrm{No}_{3}-} \simeq 1$, we have

$$
v=k_{2} K_{e}^{1 / 2} \exp (\Delta \varphi F / R T) \text {. }
$$

$K_{e}$ is the equilibrium constant corresponding to reaction (C1). Equation (58) indicates that $b$ is equal to $R T / F$.

Possibility $(b)$. As in this case, the degree of coverage by oxygen atoms might be appreciable, the rate equations of the partial reactions are

As before we have

$$
\begin{aligned}
v_{2} & =k_{2} a_{\mathrm{O}^{2}-}\left(1-k^{\prime} a_{\mathrm{o}}\right) \exp (\Delta \varphi F / R T), \\
v_{-2} & =k_{-2} k^{\prime} a_{\mathrm{O}} \exp (-\Delta \varphi F / R T), \\
v_{3} & =k_{3} k^{\prime 2} a_{\mathrm{O}}{ }^{2}
\end{aligned}
$$

$$
\begin{aligned}
w_{2} & =k_{2} a_{\mathrm{O}^{2}-} \exp (\Delta \varphi F / R T), \\
w_{-2} & =k_{2} a_{\mathrm{O}^{2-}} \exp (\Delta \varphi F / R T)+k_{-2} \exp (-\Delta \varphi F / R T), \\
w_{3} & =k_{3} k^{\prime} a_{\mathrm{O}} .
\end{aligned}
$$

The rate of the reaction results from $(62),(63),(64)$ and (6),

$$
\frac{1}{v}=\frac{1}{k_{2} a_{\mathrm{O}^{2}} \exp (\Delta \varphi F / R T)}+\frac{k_{2} a_{\mathrm{O}^{2}-} \exp (\Delta \varphi F / R T)+k_{-2} \exp (-\Delta \varphi / R T)}{k_{2} k_{3} k^{\prime} a_{\mathrm{O}} a_{\mathrm{O}^{2-}} \exp (\Delta \varphi F / R T)} .
$$

By equating (59) and (60) the activity of the oxygen atoms is obtained, assuming that at low overpotentials the degree of coverage is negligible

$$
a_{\mathrm{o}}=\frac{K_{2} a_{\mathrm{O}^{2}}-}{k^{\prime}} \exp (2 \Delta \varphi F / R T)
$$

Assuming that $k_{2} \gg k_{3},(65)$ and (66) yield

$$
v=K_{2}^{2} K_{e} k_{3} \exp (4 \Delta q F / R T)
$$

and the Tafel slope approaches the value $R T / 4 F$. 
At large overpotentials equation (65) gives

$$
v=k_{3} k^{\prime}\left(a_{\mathrm{o}}\right)_{\mathrm{sat}}
$$

and consequently $b$ tends to infinity.

Possibility (c). In analogy to possibility (b) the rate equations of the partial reactions are (59), (60) and

$$
v_{4}=k_{4} k^{\prime} a_{0} \exp (\Delta \varphi F / 2 R T) .
$$

The probability factors are given by (62), (63) and

According to (6) we obtain

$$
w_{4}=k_{4} \exp (\Delta \varphi F / 2 R T) \text {. }
$$

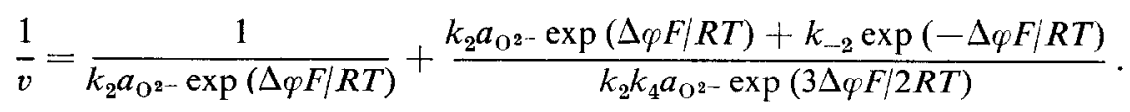

Considering that $k_{2} \gg k_{4}$, at low overpotentials (71) becomes

and $b=2 R T / 5 F$.

$$
v=K_{2} K_{e}^{1 / 2} k_{4} \exp (5 \Delta q F / 2 R T),
$$

At large overpotentials (71) gives

and consequently $b=2 R T / F$.

$$
v=k_{4} \exp (\Delta \varphi F / 2 R T)
$$

\section{The likely mechanism of the anodic reaction at low temperatures}

Results at low temperature indicate an electrode capacitance which is identifiable at the reversible potential with that of the interfacial double layer of the electrode. But the capacitances estimated from the $t_{1}{ }^{\prime}$ constants in the overpotential decay are too large to be related to the double layer of the electrode. However, the kinetics of the electrochemical process is formally analogous to those observed for the over-potential decay of a polarized electrode through discharge of the double layer condenser.

Two processes are likely to be involved since two distinct slopes in the decay curves are found. These processes could be either consecutive or alternative. That which is observed at lower overpotentials has an $i_{0} \cong 4 \times 10^{-8} \mathrm{~A} / \mathrm{cm}^{2}$ and $b=R T / F$, whilst the other observed at high overpotentials has an $i_{0} \cong 3 \times 10^{-5} \mathrm{~A} / \mathrm{cm}^{2}$ and $b=2 R T / F$. The Tafel slopes resulting from current/potential curves are $2 R T / F$ as the electrode overpotentials are high enough. Those figures show that the two processes concerned are consecutive.

The analysis we have made above favours mechanism B as the likely one which could explain most of the features of the anodic reaction occurring at low temperature. If reaction (B1) is the rate-determining step, $b$ must approach $2 R T / F$ at high overpotentials, while if (B2) is rate-controlling at low overpotentials, $b$ should be $R T / F$. It is also true that when the overpotential approaches infinity the rate of (B2) reaches a limiting value, but as we are dealing with a chemical type of reaction, it is reasonable to expect this to occur probably at much higher overpotentials.

Under the above mentioned circumstances the rate of the total reaction, if (BI) or (B2) are rate-determining steps, is given by (11) and (35) respectively. If we interpret that the change of slope in the decay curves occurring when the electrode potential reaches a value $\Delta \varphi_{t}$ is due to a change in the mechanism of reaction, at $\Delta \varphi_{t}$ we can write

$$
k_{1} \exp \left(\Delta \varphi_{t} F / 2 R T\right)=K_{1} k_{2} \exp \left(\Delta \varphi_{t} F / R T\right),
$$


which means that (B1) and (B2) occur at the same rate when the electrode overpotential is $\Delta \varphi_{t}$. Since the experimental value of $\Delta \varphi_{t}$ is, at $T=261^{\circ} \mathrm{C}$, equal to $300 \pm$ $50 \mathrm{mV}$, by inserting it in equation (74), we find that the relationship between the rate constants is

$$
\frac{k_{1}}{K_{1} k_{2}}=\frac{k_{-1}}{k_{2}}=26 .
$$

This figure can be used as a normalization factor for the velocity to show the dependence of the rate equation on electrode potential when (B1) or reaction (B2) are ratedetermining steps. In Fig. 12 both rate equations are plotted assuming that $k_{1}=1$, showing a change of the rate-determining step occurring at $\Delta \varphi_{t}$.

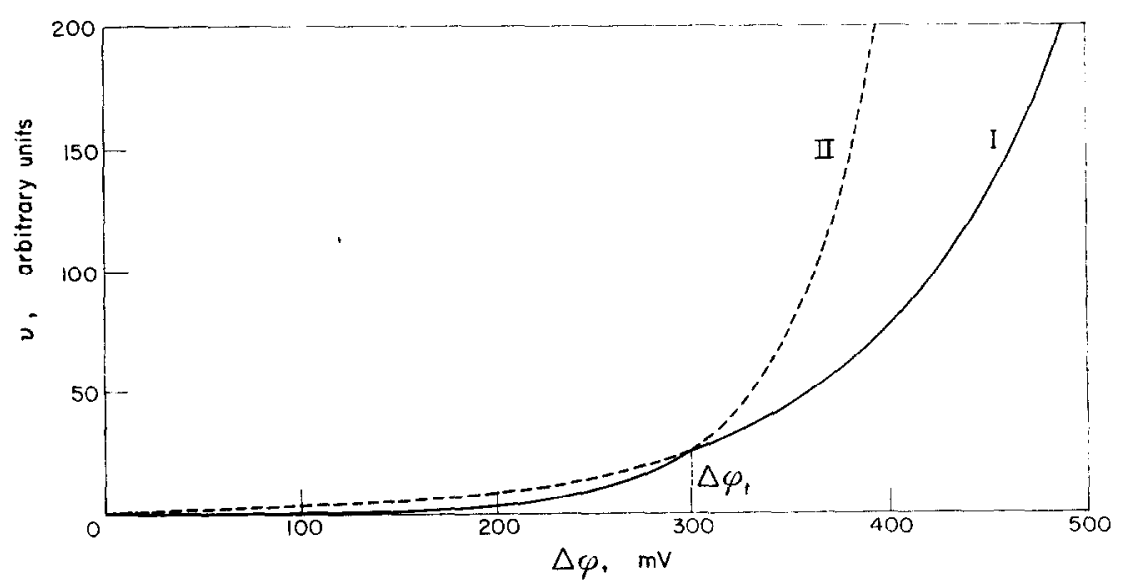

Fig. 12. Plot of equation (11), curve I, and equation (35), curve II, assuming $k_{1}=1$ and the relationship established in (75).

The ratio established in (75) is, for a constant temperature, the limiting ratio we could expect for the exchange current densities resulting from both reaction schemes, if the activity of the reacting species in both cases is unity. This is quite reasonable when reaction (B1) is the rate-determining one, but is very unlikely when (B2) is rate-determining, because then the activity of the reacting species should probably be less than unity. Hence, we should expect an experimental ratio of both exchange currents larger than the figure given by (75), and this is certainly the casc if data calculated from decay curves and extrapolation of Tafel lines, referred to a constant temperature, are considered.

Consequently, according to the foregoing discussion, the experimental energy of activation in the region where (B1) is rate-determining, as follows from (11), must correspond to the activation energy of (B1).

Finally, if (B1) and (B2) are involved in the mechanism of the anodic reaction as described above, we can also advance a probable explanation of the pseudo-capacitance estimated from the decay curves, which would result from a steady concentration of the intermediate formed on the electrode surface.

\section{The likely mechanism of the anodic reaction at high temperatures}

To consider the likely mechanism of the electrochemical reaction at higher temperatures we must first take into account the increase of oxide-ion concentration 
in the system due to equilibrium (C1). The equilibrium constant of (C1) and its dependence on temperature has recently been determined by Kust and Duke: ${ }^{16}$ $K_{\mathrm{Cl}}\left(250^{\circ} \mathrm{C}\right)=2.7 \pm 0.3 \times 10^{-26}$ and $K_{\mathrm{Cl}}\left(300^{\circ} \mathrm{C}\right)=5.7 \pm 0.1 \times 10^{-24}$. Its value at $400^{\circ} \mathrm{C}$, estimated by extrapolation, is of the order of $1.8 \times 10^{-19}$. Considering that at high temperatures an oxygen reversible electrode is formed, the oxide-ion concentration as compared to the low temperature melt increases by a factor of the order of $10^{4}$. This fact suggests that the reaction taking place at high temperature is the discharge of oxide ions on the platinum electrode.

Therefore, according to the kinetic analysis, the results above $350^{\circ} \mathrm{C}$ can be explained on the basis of mechanism $\mathrm{C}$, if (C2) is the rate-determining step. In this case we expect the value of $b$ to be equal to $R T / F$ and independent of the current density, which should be identical whether it is calculated from the Tafel lines or from the decay curves. Consequently, the mechanism of the reaction in this case is much simpler than the process previously discussed for lower temperatures.

Mechanism $\mathrm{C}$, involving ( $\mathrm{C} 2)$ as the controlling one, indicates the amount of surface coverage by oxygen atoms should be negligible and consequently, the differential capacitance of the electrical double layer should be low, as is found.

We must state here that at the highest temperatures we have observed an increasing departure of the residual cell reversible potential from the thermodynamic data, obtained on the basis of the reversible nitrate electrode reaction. ${ }^{2}$ As a matter of fact, this departure can be corrected if the electrode potential in those cases is supposed to depend only on the pressure of oxygen gas. This is certainly a reasonable result, which indicates that at high temperature the nitrate ions tend to establish on platinum an oxygen-type electrode, as has been observed before for molten phosphates, silicates, carbonates and sulphates ${ }^{17.18}$ at temperatures around $700^{\circ} \mathrm{C}$. This would thus give further support to the idea that oxide ions actually participate in the discharge reaction when the electrolysis of nitrates is carried out at the highest temperatures.

Acknowledgement This work was financially supported by the Consejo Nacional de Investigaciones Cientificas y Técnicas of Argentina. W.E.T. thanks the Consejo for the fellowship granted.

\section{REFERENCES}

1. S. Karpatscheff and W. Patzug, Z. phys. Chem. 173, 383 (1935).

2. W. E. Triaca and A. J. Arvia, Electrochim. Acta 9, 919 (1964).

3. W. E. TriaCA and A. J. Arvia, Electrochim. Acta 9, 1055 (1964).

4. J. Jordan, K. A. Romberger and M. W. Young, Angew. Chem. 75, 1031 (1963).

5. A. J. Arvia, A. J. Calandra and H. A. Videla, Electrochim. Acta, 10, 33 (1965).

6. H. A. Videla and A. J. Arvia, Electrochim. Acta, 10, 21 (1965).

7. W. F. RICHFSON and M. EISENBERG, J. Electrochem. Soc. 107, 642 (1960).

8. W. R. Busing and W. J. Kauzmann, J. Chem. Phys. 20, 1129 (1952).

9. A. N. Frumkin, Disc. Faraday Soc. 1, 57 (1947).

10. J. O'M. Bockris and E. C. PotTer, J. Electrochem. Soc. 99, 169 (1952).

11. B. E. Cunway and P. L. Bourgault, Canad. J. Chem. 37, 292 (1959).

12. C. A. Christiansen, $Z$. phys. Chem. B28, 303 (1935).

13. C. A. Christiansen, ibid., B33, 145 (1936).

14. J. O'M. Bockris, J. Chem. Phys. 24, 817 (1956).

15. F. R. Duke, J. Chem. Educ. 39, 57 (1962).

16. R. N. Kust and F. R. Duke, J. Amer. Chem. Soc. 85, 3338 (1963).

17. H. Flood and T. Førland, Disc. Faraday Soc. 1, 302 (1947).

18. G. J. JANZ, F. Colom and F. Saegusa, J. Electrochem. Soc. 107, 581 (1960). 